\title{
A comparison of the implementation of food hygiene standards between government and private catering establishments
}

\author{
E. M. Abogrean ${ }^{1}$ \& L. O. Abugrain ${ }^{2}$ \\ ${ }^{1}$ The National Authority for Scientific Research, Libya \\ ${ }^{2}$ Faculty of Agriculture, Libya
}

\begin{abstract}
A comparison of the implementation of food hygiene standards between government and private catering establishments was conducted throughout 2010 in Tripoli, Libya. The study focused on whether there is an association between the two types of establishments, and the application of food safety measures by employees.

The food handlers' questionnaire was designed to assess food safety and hygiene measures resulting from staff training as well as to detect the similarities and the differences between the two types of institutes in application of food hygiene standards. Respondents were asked about food hygiene practices in their catering institutions, their attitude towards a range of food hygiene related issues and habits, that are considered crucial during food preparation, whereas the supervisors (managers) questionnaire was intended to investigate their awareness of the hazards, control, and any performance plans relating to their catering.

The results showed that the level of implementation of food hygiene standards in private catering institution is higher than in the government ones. In addition, the supervisors of private institutions were more aware of food safety and food hygiene than the supervisors of government institutions. In general, the performance of food handlers and supervisors working in private sector is better than the performance of those working in government sector.
\end{abstract}

Keywords: food hygiene, implementation, catering, government and private. 


\section{Introduction}

The processing and handling of food, and catering are very important activities. They need the awareness of all staff in the field to their importance in public well being. The changes in life style and quality made it important to enhance and suggest new measures for food safety [1].

Within establishments that provide services include food making and presentation on a large scale, the catering operations are complex and have the potential to produce disastrous consequences for health, if the strictest principles of hygiene are not maintained. Even if food safety is considered a prime parameter in food catering, most foods produced by caterers are potentially hazardous foods (PHFs). Therefore, employees in such institutions should understand what they need to do and how (applied HACCP). Many efforts for improving food hygiene and assuring food safety are put in place at various levels of food processing [2].

The food control system in Libya is based on the Health Law No. 106 and Standards Law No. 5 (adopted in 1990), which prohibit the distribution and selling of fraudulent and unsafe foods and food which is not compliant with the standards issued by the National Centre for Standards and Codes [3]. The National Centre for Food and Drug Control was established as the specialized health authority, responsible for accepting or rejecting any imported food consignments. The Centre authority is to monitor and inspect all food production, distribution and display outlets. In 2003, the Centre has inspected 9,305 imported food items. A total of 220 shipments were rejected and about 19,131 samples were analyzed. Additionally, the Centre has conducted a total of 2,310 field visits to domestic markets, including manufacturers, schools, wholesale and retail outlets, restaurants and slaughterhouses.

Recently, the General Public Committee of Libya established a National Codex Committee and nominated the National Centre for Standards as the focal contact point for Codex matters. Consumers' protection associations have only been recently established in Libya, the first being established in February 2005. For this reason, consumers have not been previously involved in the preparation of national standards. However, major sectors of the community actively participate in the preparation of national standards, e.g.: scientific research institutions, academia, industry, marketing, legislation, depending on the nature of standards. The newly established consumer association will participate in this activity [3]. The purpose of this study is to investigate the level of food safety process within government and private institutions in Tripoli-Libya.

\section{Methodology}

Aspects considered were methods of data collection sampling distribution and collection of questionnaires. 


\subsection{Methods of data collection}

In order to achieve the aims and the set of objectives outlined, consideration was laid out to collect the evidence required. The big question here or them being “does the type of institution have any influence on food hygiene practices?” Both primary and secondary data research methods were used. Primary data as being the original work that has been gathered with the use of questionnaires and risk audit survey [4]. Secondary data includes, both raw data and published summaries were fixed in order to supplement the core information to be investigated. Primary data was gathered through the use of questionnaires and risk based audits and analyzed. The findings were supported and collected by the secondary data highlighted in the literature survey.

\subsection{Preliminary data using questionnaires}

The questionnaire is the foundation for original research, which ties the population and the research question. In the use of the questionnaire the questions were used to allow the researcher to reach conclusions relating to the sub problems, the problems, the hypotheses and the aims of the research. Each individual was asked to respond to the same set of questions, which provided information for the quantitative analysis. The researcher tried to ensure that the questionnaire would give the information needed, on problem at the analysis and interpretation stage, as well as begin acceptable to the subject. Relevancy was based on the achievement of objectives, since it would be difficult to make a repetitive collection of data be trying to use another questionnaire.

As an acceptable approach to data collection, to obtain maximum response rate validity and reliability, several attempts at working to remove ambiguity, understanding what was asked, checking language and jargon free, an explanation of the purpose of the questionnaire and polite testing were maintained [5]. The researcher refined the questionnaire to meet the needs of the research, by a polite sample as well as obtaining approval from the supervisor.

\subsection{The pilot questionnaire}

Pilot studies collect data from the ultimate subject of the research project to serve as a guide for the larger study. The results of the survey are used to check that all questions and instructions are clear and to enable the researcher to remove any items which do not yield usable data [6]. The designed questionnaire -based survey was piloted with group similar to the final population in the sample. The pilot was carried out at Tripoli Private Hospital catering department. This was appropriately selected to try and establish problem that could be encountered when carrying out the actual research in Libya. The productions staff make up the bulk of the catering workforce who are involved fully with the operations/work of the catering department and eight of these were used for the polite study. Two supervisors were used for the supervisor's questionnaire from the same institute. 


\subsection{The final questionnaire}

The questionnaire included mostly closed questions rather than open since the sample respondents were found to be from group of lower socioeconomic level with limited education having English language communication problem, read poorly or not at all. In which case the researcher opted to translate the question into Arabic (the country's language) and sat down with the respondents to help complete the questionnaire. Some opted to have the questionnaires translated by their colleagues. Thus more open questions would have ultimately been difficult and boring for them to respond to which would have put a strain on the research as a whole.

Category questions were also mostly used where the respondents were required to fit an answer to one category. Categories included all possibilities and the layout was made clear with boxes to refer to each response category, placed closely to the appropriate text. The questionnaire started off with simple straightforward questions about the respondent and flowed into matter of opinion through the choices of statements which expected response of either, strongly agree, and agree, neither agree/disagree, disagree and strongly disagree. Different aspects of hygiene measures were grouped together to allow easier understanding and pattern of the hygiene standards areas concerned. The questionnaires for both food handlers and supervisors comprised A4 size pages each, to give boost to easy response by not appearing to be long.

\section{Results and discussion}

The response of all institutions, which were included in this research, has been one of real interest and cooperation. This verified the fact that more and more establishments are becoming conscious of the importance of basic hygiene practices that is to date are still lacking in most of our food establishments.

\subsection{Results of questionnaire for food handlers}

One hundred and sixty copies of the questionnaire were distributed. The questionnaire was completed and collected by a total of 130 (77\%) respondents.

Out of the 130 respondents the total number of males were 100 (77\%), and 30 (23\%) were females. From the two different types of institutions investigated, the number of male respondents are higher than female's as seen in Table 1 . The two

Table 1: $\quad$ Sample population by classification of sex.

\begin{tabular}{llll}
\hline Type of Institution & Sex & Count & Percentage \\
Government & Male & 63 & $75 \%$ \\
\multirow{2}{*}{ Private } & Female & 21 & $25 \%$ \\
& Male & 37 & $80 \%$ \\
\multirow{2}{*}{ Total } & Female & 9 & $20 \%$ \\
& Male & 100 & $77 \%$ \\
& Female & 30 & $23 \%$ \\
\hline
\end{tabular}


different types of institutions show a significantly high number of male caterers than females. The percentage of males to females is similar to it in developed countries, but different to it in developing countries.

\subsection{Age range}

For the sake and nature of this research, establishing any differences in the preparation/production measures of food hygiene, it was deemed necessary to find out whether the age ranges of employed staff in different institutions differs greatly. The respondents age range showed that the highest number of employees age was in the range of 25-34 years, 64 (55\%) in all the institutions, followed by 35-44 years 38 (23\%), then 45-54 years 16 (12\%). The respondents age ranges and percentage are summarized in Figure 1 below. Figure 1 shows the age group range of 25-34 years is the biggest group (55\%), most people of this group have experience of more than two years. This proves that irrespective of the type of institutions they do not tend to employ young workforce i.e. 15-24 years, whereas in Libya believe that older worker are more experienced.

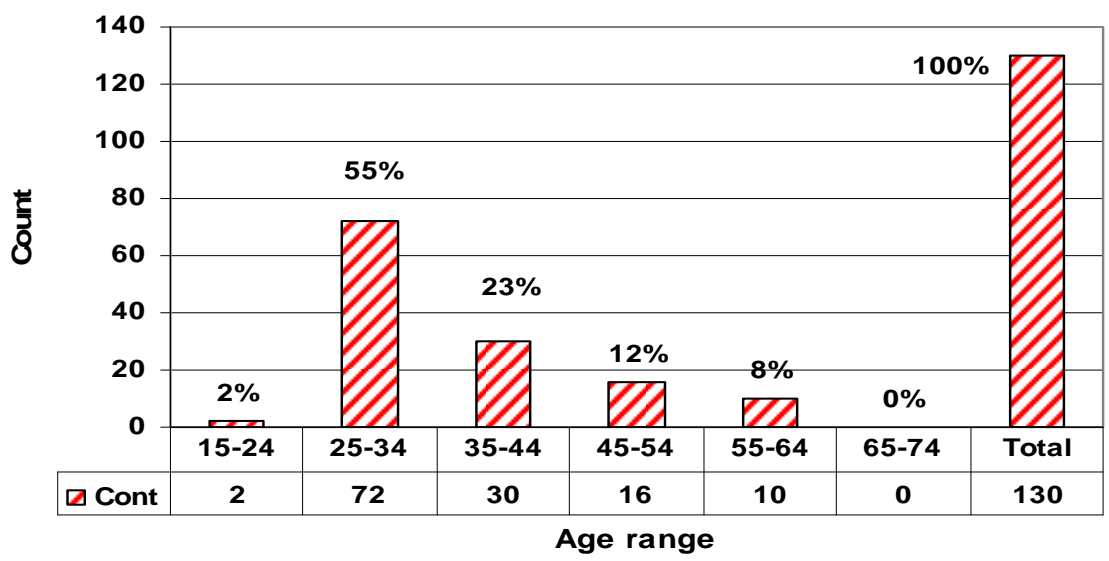

Figure 1: $\quad$ Respondents age range and percentage for all the institutions.

\subsection{Employment record and any food hygiene training}

The respondents' employment records were also considered as well as whether during this employment record have had any food hygiene training. Records of employees training are displayed in Figure 2. There were 9 employees from government institutions and 2 employees from private institutions had no training while the reminder have had different training periods.

\subsection{Formal (exam/certificate)}

With regards to whether the food handlers had any training and whether it was formal or not, from government institutions 58 (69\%) had various training, 
17 (20\%) had formal training and 9 (11\%) had none. While private institutions 39 (85\%) admitted to having had formal training, 5 (11\%) had informal training and 2 (4\%) had no training. Figure 3 displays training experience acquired by employees in each sector. The most striking result emerged from this study was that private institutions were dominant on formal training (exam/ certificate) by $85 \%$ compared to government institutions (20\%), while government institutions were dominant on informal type of training.

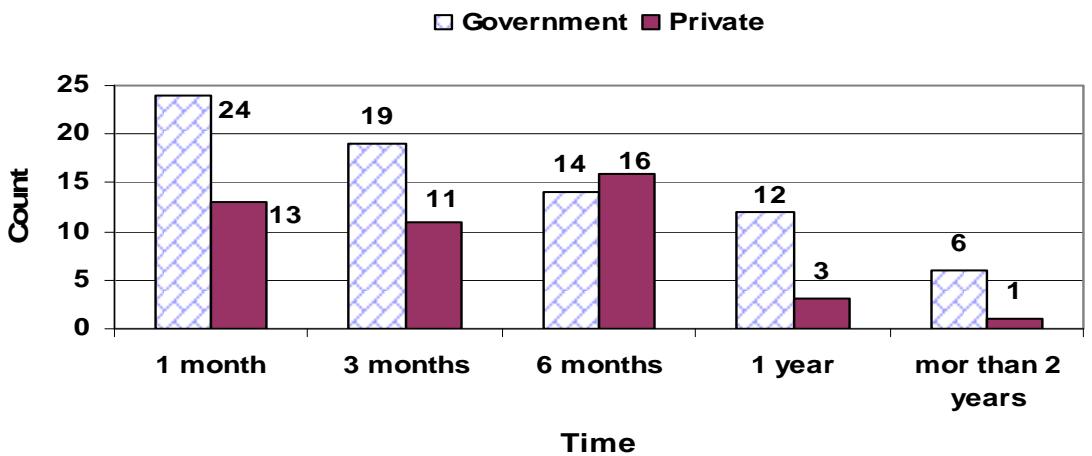

Figure 2: $\quad$ Respondents’ employment record.

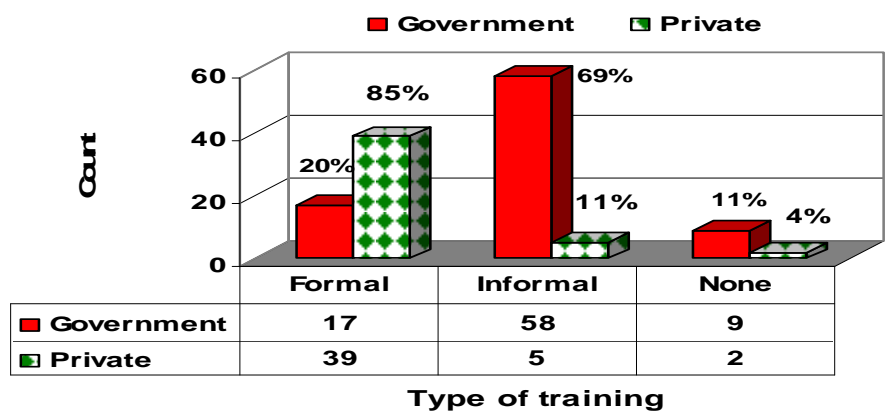

Figure 3: $\quad$ Food hygiene training experience.

\subsection{Rating of training offered}

The rating of training offered to them their job were 48 (64\%) of those in government institutions felt it was good and only 15 (20\%) felt it was excellent, while in private 32 (73\%) felt it was excellent and 6 (14\%) felt it was good. Respondents' views are shown in Figure 4.

\subsection{Length of time since the last training}

The food handlers last training records is presented in Table 2. Overleaf the information is also of importance in investigating if hygiene measures improve due to staff training. 
A large percentage showed that even though some form of training has been offered, in private institutions it has either been recently reviewed or undertaken which reflected to be either 1-6 months ago and least being about two years back. Whereas there was setback in food handlers training is shown in government institutions which reflect no recent training, but $56 \%$ of staff having had their last training 19 months and plus back.

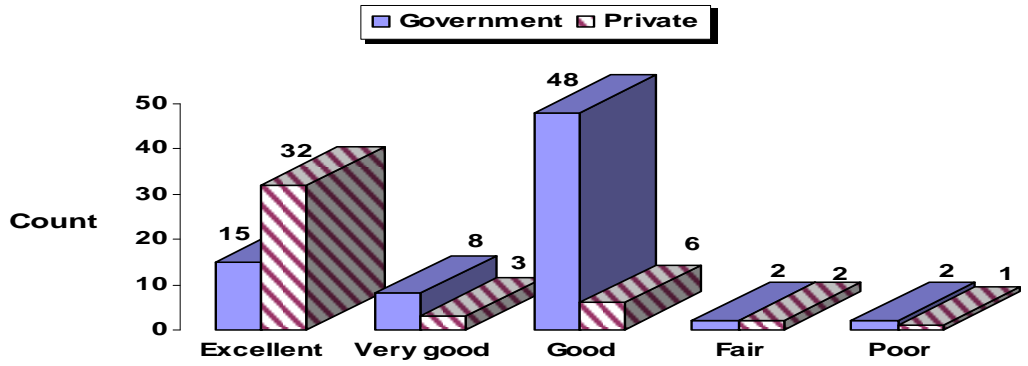

Figure 4: $\quad$ Score of training acquired.

Table 2: $\quad$ Length of time since the last training sessions took place.

\begin{tabular}{||l|l|l|l|l|l|l||}
\hline $\begin{array}{c}\text { Type of } \\
\text { institution }\end{array}$ & \multicolumn{1}{|c|}{$\begin{array}{c}1-6 \\
\text { months }\end{array}$} & \multicolumn{1}{|c|}{$\begin{array}{c}7-12 \\
\text { months }\end{array}$} & $\begin{array}{c}13-18 \\
\text { months }\end{array}$ & $\begin{array}{c}19-24 \\
\text { months }\end{array}$ & $\begin{array}{c}\text { 25+ } \\
\text { months }\end{array}$ & $\begin{array}{c}\text { Not } \\
\text { applicable }\end{array}$ \\
\hline Government & $4(5 \%)$ & $7(8 \%)$ & $5(6 \%)$ & $47(56 \%)$ & $12(14 \%)$ & $\begin{array}{l}9(11 \%) \\
2(4 \%)\end{array}$ \\
Private & $28(61 \%)$ & $8(17 \%)$ & $5(11 \%)$ & $2(4 \%)$ & $1(2 \%)$ & $2 \%(4 \%)$ \\
\hline
\end{tabular}

\subsection{Results of questionnaire for supervisors}

Concern is not only with food handlers but managers of mass catering institutions who should exercise some form of quality control over the whole establishment. Monitoring and control are the essential functions of management. Libyan Food Control Act 1990 Section 106 states that "Any person who sells, prepares, packages or stores any food under unhygienic conditions shall be guilty of an offence”. In this instance it is the main duty of the supervisor/manager to take all lawful necessary and reasonably practicable measures to ensure food safety and food hygiene.

The questionnaires distributed were 33 hard copies. The questionnaire was completed and collected by a total of 24 (73\%) respondents. This part of the research is based on data collected from a population sample of 24 respondents, which is fifteen from government institutions and nine from private institutions who managed to satisfactorily complete the questionnaire. The respondents of male and female from both institutions are presented in Figure 5. Out of the 24 respondent, from the government institutions 53\% was male and $47 \%$ were females whereas the private institution $56 \%$ was male and $44 \%$ were females. The findings show that in the two different types of institutions males are still higher than females even in the supervision sector. 


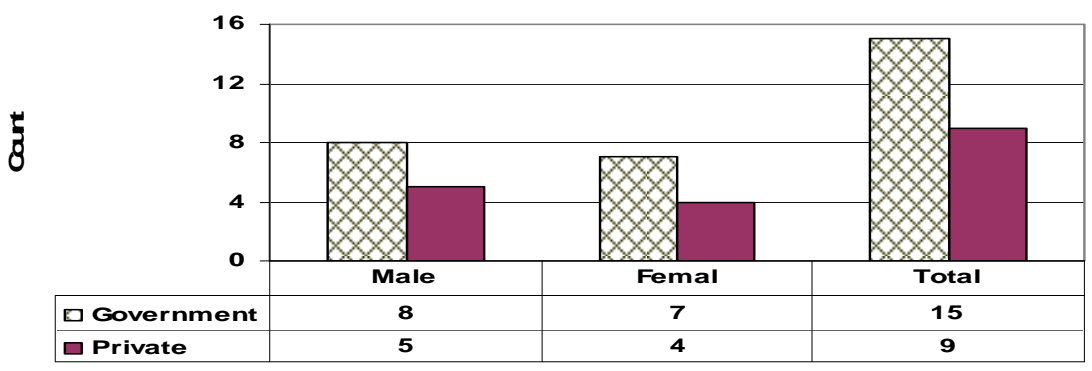

Figure 5: Gender of supervisors in government and private institution.

\subsection{Respondents' employment duration}

The supervisor's management duration in both institutions was also considered in this research. As presented in Figure 6, the majority of supervisor had in the business for an average of 4-6 years, $60 \%$ and $67 \%$ for government and private institutions, respectively. On the other hand there was $20 \%$ from government have been in the business for more than 7 years. The remaining percentages of government and private have been in the business for 3 years or less.

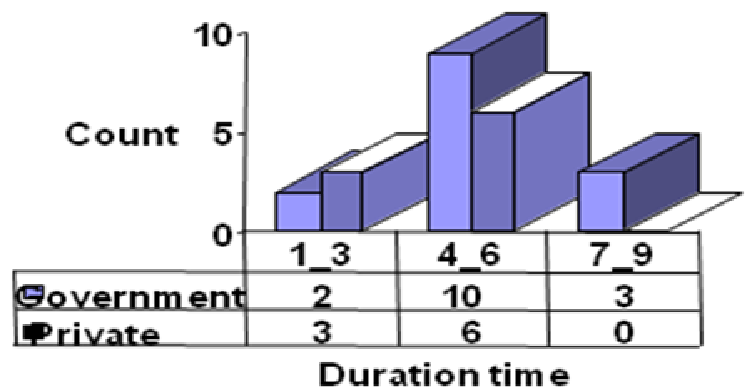

Figure 6: Supervisor duration experience for both institutions.

\subsection{Risk area}

Four of the supervisors are working in a high risk area and the remaining are working in low risk area. All of them agreed that the high risk area is the cooking area and the main source of high risk is coming from gas leakage. Table 3 presents the distribution of production area.

As presented in Table 3 the majority (20) of supervisors is working in a low risk area, and $17 \%$ working in a cooking area which they believed is a high risk area, like gas leakage, high temperature and high humidity. 
Table 3: Distribution of production area.

\begin{tabular}{|c|c|c|c|c|c||}
\hline & $\begin{array}{c}\text { Raw } \\
\text { material }\end{array}$ & $\begin{array}{c}\text { Production } \\
\text { area }\end{array}$ & Packaging & $\begin{array}{c}\text { Cooking } \\
\text { area }\end{array}$ & Storage \\
\hline Count of gov. & 2 & 3 & 3 & 2 & 2 \\
\hline Count of priv. & 2 & 3 & 3 & 2 & 2 \\
\hline
\end{tabular}

\subsection{Hygiene arrangement system}

Supervisors from all institutions admitted to following a hygiene arrangement system and having it documented, yet, only three types showed that they carried out and documented cleaning after, inspection of stores and delivery of new stock, temperature monitoring of foods during cooking, cooking, refrigeration, re-heating and serving. The other type admitted to tasks being carried out but not documented as shown in Figure 7.

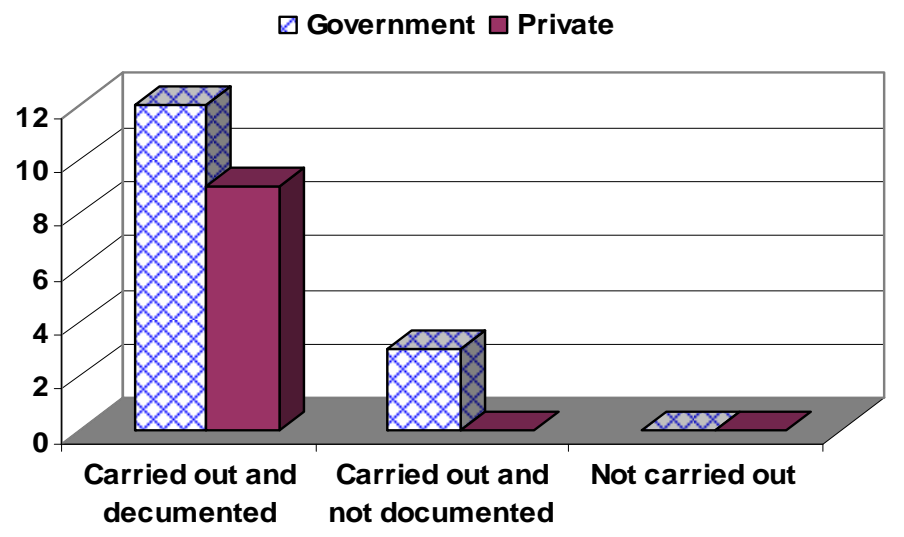

Figure 7: Hygiene arrangement system.

All supervisors in Tripoli-Libya from the two types of institutions readily agreed to following a hygiene arrangement system and having it documented, there were a few fallbacks on certain activities that were carried out in government institutions which were not documented. Even though carried out, cleaning after a day's was shown to be only documented in the private (73\%) whereas the government institutions $50 \%$ did not document. The other task, which is of most importance, checking on collection of food wastes by Council, lacked the importance of documentation in all institutions involved, as they clearly showed that even though they carried out this task, it was not documented. Although there appeared to be some lack of documentation for most of the activities carried out by government and private institutions, i.e. 
cleaning of cold rooms, general or thorough cleaning, arrangement of goods in the stores, inspection of stores, hygiene and temperature checks of delivery vehicles, inspection of raw materials etc. there has been an account that the majority of supervisors are aware of the important of carrying out the practices. However a high risk environment, starting with the raw material which the role of raw material has to play in the manufacture of finished products is critical in order to assure quality and safety standards at every step in the supply chain [2].

\subsection{Cleaning schedule and cross contamination}

With regards to cleaning schedule, all (100\%) institution admitted to following hygiene cleaning schedules. On the issue of preventing cross contamination $(100 \%)$ of the institutions, stated that their industries provided separate handling of raw/cooked foods. Government admitted to having separate utensil /chopping boards for raw and cooked foods. Responses also showed that the government provided a uniform only if it is torn or misplaced whereas private provided it essentially yearly.

To avoid cross contamination, a generally positive response to the provision of some good hygienic practices was indicated. These included separate handling of raw/cooked foods whereby $100 \%$ of all institutions responded positively. On the issue of provision of separate utensil/chopping boards for raw and cooked foods $100 \%$ of the supervisors of the private institutions responded, whereas 6 (43\%) of supervisors from the government responded. The idea here was that the government institutions seemed to be running on less adequate and efficient equipment, since the provision for these were only catered through the government's financial vote every two years requests for such equipment took ages or were sometimes never fulfilled efficiently. As opposed to the private institutions, which are solely, depend on their sect-oral financial provision, thus managing to purchase equipment whenever the need arises as well as not having many procedural steps of purchasing.

To prevent contamination during production, it should be ensured that the staff behaves in a hygienic way, which includes supplying appropriate clothing, facilities and training [7]. It has been suggested [7] that the benefit of hygienic training needs to be more widely promoted in order to encourage managerial commitment to staff training.

\subsection{Temperature control}

Since temperature control of food is very important for food safety, the positive respondents where very much aware of the basic food hygiene practices. The results of temperature checking of chilled food delivery storage, kept food hot during serving, store chill cooked foods rapidly if storing, store left over foods (cooked), follow proper cooking instructions, reheat food until piping hot is illustrated in Figure 8.

As shown in Figure 8, private institution was always 8 (89\%) and sometimes 1 (11\%), whereas in government institution was always17 (71\%) and sometimes 7 (29\%). That means the regulation of food safety in private institutions is higher 


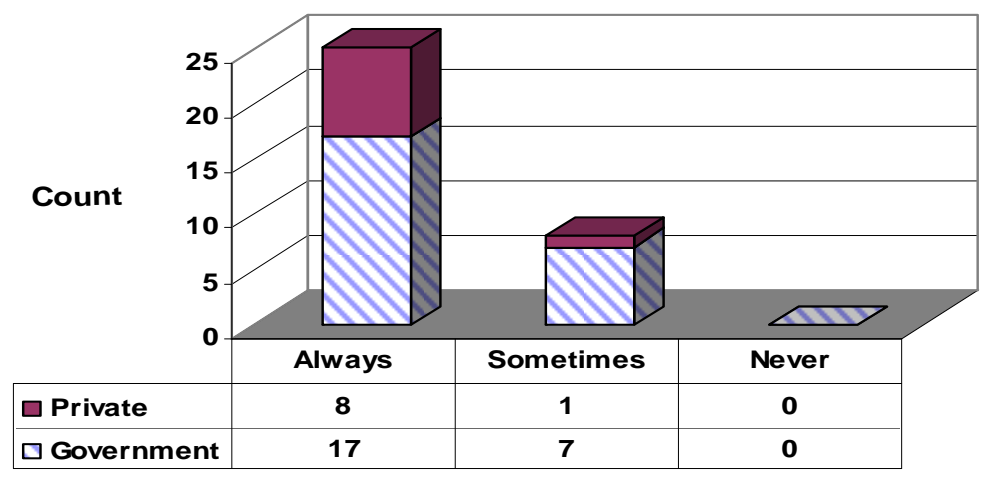

Figure 8: $\quad$ Food temperature control.

than in government institution. These positive supervisors responses showed that in all institutions the respondents were very much aware of the basic hygiene practices and they applied the Libyan regulation of food safety.

\section{Conclusions}

The results of this study indicate that there are some differences in the level of food hygiene standard in both types of catering institutions. Food hygiene standards in government institution are achieving the minimum requirements, while the private institutions achieving overall best standards. Staff of both seems to be unfamiliar with some basic principle of food hygiene, which points to inadequate training and supervision.

The research showed that the principles of hygiene do not stay the same throughout the operation or preparations in the different managed catering institutions. The private institutions still maintain high standards of food safety and hygiene measures in that the general policies, e.g. HACCP (critical control points), are monitored through periodic checks. Staff in these institutions is aware of the high penalty of losing their jobs by being instantly dismissed if they do not follow such practices, whereas with government most workers are fairly assured that they have their jobs secured regardless of whatever situation.

In investigating parts of the safety standards which cause difficulties when using the hygiene system, the lack of financial resources, unskilled workers who have limited education, unavailability of formal training especially in government institutions and even when training is given these workers often do not find it easy to take advantage of it. This could be reduce job satisfaction to the fact that they feel menial by not fully understanding why they have to follow certain aspects of the food safety measures. In developing country like Libya usually had to explain the relationship between cleanliness and health to workers from an inadequate socioeconomic and educational background. Therefore workers tend to change their employment frequently due to the humble boring and dull job that appears to be the case to them. 


\section{Acknowledgements}

An investigation of food hygiene standards by government and private in Libya was supported by the (National Authority for Scientific Research-Libya). Therefore we express our sincere gratitude to the head of the National Agency for Scientific Research and all the staff members.

\section{References}

[1] Richard A. S, (2004), Hygiene for Management, A text for food safety courses, 11th edition, published by Highfield Co. UK Limited.

[2] Sheward E, (2005), Aviation Food Safety. Foreword by Sara Mortimore, 1st edition, Blackwell Publishers Ltd, Oxford, UK.

[3] FAO and WHO (2005). Report of the third session coordinating committee for the near East region.

[4] Saunders M. L. P. and Thornhill A. (1997). Research Method for Business Students. Financial Times Pitman Publishing. London.

[5] Bell J. (1993). Doing Your Research Project; A Guide for First-time Research in Education and Social Science. Second edition. Open University Press. Buckingham.

[6] Ward G. (1995). Catering Questions and Answers; Food Hygiene. Corner Publications. London.

[7] Jones P, (2004), Food Catering, 2nd edition, British Cataloguing in Publication Data, Oxford 